\section{WATCH: Microcomputer programs to collect and analyze behavioral observations based on focal-animal sampling}

\section{FRED W. KOONTZ \\ Department of Zoological Research, National Zoological Park Washington, D.C. 20008}

Observational studies of behavior often use a focalanimal sampling method (Altmann, 1974). The focal animal is observed for a predetermined period of time, during which all occurrences of specified behaviors and the time at which they take place are recorded. From these data, frequencies, rates, and durations of the specified behaviors can be calculated. Also, time budget estimates and behavioral sequence analysis are possible. When focal-animal sampling is used, a microcomputer can increase data collection efficiency and facilitate data analysis.

WATCH is a software package that was written for the Tandy/Radio Shack TRS-80 Model I microcomputer; the programs are used to collect, edit, and analyze observational data based on focal-animal sampling. Data are stored on floppy disk files that can be transferred, by commercially available communication software, to larger mainframe computers for long-term storage or for additional analysis. WATCH contains one machine language program and three programs written in TRS disk BASIC. Portability limitations and the power requirements of the TRS-80 restrict this system to studies using captive animals.

System Requirements. The programs described in this paper were written for a TRS-80 Model I microcomputer with an expansion interface. Additional components of the system include 48-KB RAM, two disk drives, an Epson MX-80 printer, an RS-232-C board, and an Alpha Products I/O Interfacer $2 .{ }^{1}$ Tandy/Radio Shack's TRSDOS operating system is used. With program modifications, the minimum hardware require. ments are 32-KB RAM and one disk drive. A RS-232-C board is necessary to transfer files to a mainframe computer. The I/O Interfacer 2 is optional; it attaches to the $\mathrm{I} / \mathrm{O}$ bus and is needed to operate an interval timer that can be used for periodic data sampling. The TRS- 80 is stored on a movable cart so that it can be easily positioned in front of a study animal's cage.

Program Descriptions. KLOCK/CIM is a machine language program that initializes and updates a real-time clock; it uses a 40-msec heartbeat signal generated in the expansion interface. This program is loaded into high memory and can be run simultaneously with the data collection program (called OBST80/BAS) to provide the time of day.
OBST80/BAS is a TRS disk BASIC-interpreted program that is used to collect and to store on disk a list of behaviors and the times at which these behaviors occurred. Before using the program, the researcher must assign a unique two-digit code number for each behavior pattern under investigation. During an observation, the user simply enters the specific two-digit code whenever the corresponding behavior is observed. "The program assigns to each behavior code the time at which it was entered (in decimal hours, $\pm .03 \mathrm{sec}$ ) and temporarily stores each code time in an ordered array. At the end of a timed session (or a maximum of 1,000 behaviors), the code times are stored in the observed sequence on a floppy disk, along with an observation identification code. The data can also be output to the printer to provide an immediate hard copy. The disk files can be later transferred to a mainframe computer. I use ST$80 \mathrm{D}^{2}$ communication software and transmit the data files to a UNIVAC 1140 mainframe computer. OBST 80/ BAS also contains a subroutine that can control an interval timer connected to the I/O bus. It is programmed to turn on a small red light for $1 \mathrm{sec}$ at 1 -min intervals; this is used for periodic sampling. The interval timer's parameters can be easily changed for different applications by simple modification of the program.

EDIT/BAS is a TRS disk BASIC-interpreted program that can load a requested OBST80/BAS data file from disk storage and allows the file to be edited. The data can be rapidly scanned on the video monitor to search for obvious mistakes. The program has options for changing, deleting, and inserting data to correct input errors made during an observation session. Also, the files can be sent to the printer to produce printed copies of the data.

RECORD/BAS is a TRS disk BASIC-interpreted program that was written for my particular needs. It is provided in WATCH as an example that can be modified or used as a model for writing an analysis program. RECORD/BAS can load from one to five OBST80/BAS files, and for each file the program totals the frequencies and durations of the behavior patterns observed. In addition, it calculates several indexes by combining frequency counts of certain behaviors. A summary report is generated and printed on the printer.

Limitations. The user must assign a two-digit code number to each behavior pattern. Therefore, OBST80/ BAS is limited to 99 behavioral patterns. Also, it is assumed that the focal animal performs only one behavior at a time. If simultaneous combinations of behaviors occur, then each combination of behaviors must be assigned a unique code number.

Availability. WATCH is available from Fred W. Koontz, Department of Zoological Research, National Zoological Park, Washington, D.C. 20008. Any request should 
include a blank 5.25 -in. soft-sector floppy disk and $\$ 3$ for printing costs of the program listings and user guide.

\section{REFERENCE}

Altmann, J. Observational study of behavior: Sampling methods. Behaviour, 1974, 49, 227-267.

\section{NOTES}

1. Interfacer 2 is available from Alpha Products, 79 th Street, Woodhaven, New York 11421.

2. ST-80D is a trademark of Lance Micklus, Inc. It is available from Lance Micklus, Inc., 217 South Union Street, Burlington, Vermont 05401 .

(Accepted for publication June 15, 1982.) 